\title{
Realized correlated responses to artificial selection on pre-adult life-history traits in a butterfly
}

\author{
K Fischer $^{1}$, BJ Zwaan ${ }^{2}$ and PM Brakefield ${ }^{2}$ \\ ${ }^{1}$ Department of Animal Ecology I, Bayreuth University, Bayreuth, Germany and ${ }^{2}$ Institute of Biology, Leiden University, Leiden, \\ The Netherlands
}

\begin{abstract}
We use artificial selection experiments targeted on egg size, development time or pupal mass within a single butterfly population followed by a common-garden experiment to explore the interactions among these life-history traits. Relationships were predicted to be negative between egg size and development time, but to be positive between development time and body size and between egg size and body size. Correlated responses to selection were in part inconsistent with these predictions. Although there was evidence for a positive genetic correlation between egg and body size, there was no support for genetic correlations between larval development time and either egg size or
\end{abstract}

pupal mass. Phenotypic correlations among the three target traits of selection gave comparable results for the relationships between egg mass and development time (no association) as well as between egg mass and pupal mass (positive association), but not for the relation between development time and pupal mass (negative phenotypic correlation). In summary, correlated responses to selection as well as phenotypic correlations were rather unpredictable. The impact of variation in acquisition and allocation of energy as well as of the benign conditions used deserve further investigation.

Heredity (2007) 98, 157-164. doi:10.1038/sj.hdy.6800919; published online 15 November 2006

Keywords: Bicyclus anynana; body size; correlated response; developmental time; egg size; trade-off

\section{Introduction}

Offspring size, development time and body size are traits of key importance within each individual's development, and all of these are related to fitness (e.g. Stearns, 1992; Fox and Czesak, 2000; Roff, 2002). Egg size in insects, for instance, can considerably affect the fitness of the progeny resulting from these eggs; larger offspring were frequently found to mature earlier, to have improved ability to avoid or withstand predation or competition, or to survive better in stressful environments compared with the small offspring (Azevedo et al., 1997; Fox and Czesak, 2000; Roff, 2002; Czesak and Fox, 2003; Fischer et al., 2003, 2006). The considerable and wide-ranging ecological importance of a large body size is clearly demonstrated by its positive effect on various fitnessrelated traits (e.g. fecundity, metabolic rate, dispersal, competitive, predatory and defensive abilities, capability to withstand starvation and desiccation; SchmidtNielsen, 1984; Blanckenhorn, 2000). Regarding development time, quick development is usually at a selective premium, reducing exposure time to predators and parasitoids and enabling rapid reproduction and thereby more generations a year (for multivoltine species; Stearns, 1992; Partridge and French, 1996; Roff, 2002; but Prasad and Joshi, 2003).

Correspondence: Dr K Fischer, Department of Animal Ecology I, Bayreuth University, PO Box 101 251, D-95440 Bayreuth, Germany.

E-mail:klaus.fischer@uni-bayreuth.de

Received 1 August 2006; revised 12 September 2006; accepted 28 September 2006; published online 15 November 2006
Life-history theory, which attempts to explain differences in development, growth and reproduction in the sense that they have been shaped by natural selection, predicts that fitness-related traits such as the ones mentioned above should be involved in trade-offs (Stearns, 1992; Roff, 2002). The existence of trade-offs, meaning that a beneficial change in one trait is linked to a detrimental change in another, is a fundamental assumption of life-history theory (Stearns, 1992; Roff, 2002). They are also expected to play a major role in the maintenance of genetic variation underlying fitness-related traits. If such trade-offs did not exist, selection is expected to drive traits that are related to fitness to their limits imposed by history and design, and the fact that many life-history traits are maintained well within those limits suggests that trade-offs must exist (Stearns, 1989, 1992).

Trade-offs are usually measured as phenotypic or genetic correlations among traits (Stearns, 1992). From an evolutionary perspective, trade-offs are particularly important if they have a genetic basis. Genetic correlations among traits may result from pleiotropy or linkage disequilibrium, and have been documented for many morphological and life-history traits (e.g. Falconer and Mackay, 1996; Roff, 1997). If two traits are genetically correlated, selection for a change in one trait can result in the evolution of a change in the second trait. Thus, tradeoffs as well as genetic correlations may constrain trait evolution.

The measurement of constraints, however, has attracted substantial criticism and controversy (Gould and Lewinton, 1979; Pease and Bull, 1988; Houle, 1991; Stearns, 1992; Pigliucci and Kaplan, 2000; Sgrò and Hoffmann, 2004; Frankino et al., 2005). This is partly 
because there are many reasons for why an expected trade-off or constraint might not be found in practice, including variation in acquisition and allocation processes or variation in third traits in sufficiently complex multivariate systems (e.g. Van Noordwijk and De Jong, 1986; Pease and Bull, 1988; Gromko, 1995; Reznick et al., 2000; Blows and Hoffmann, 2005). One methodology that has been proven reliable and informative is artificial selection (Maynard-Smith et al., 1985; Hill and Caballero, 1992; Stearns, 1992). If traits are genetically correlated, selection on one trait will lead to a correlated response in other traits. This approach can be a powerful tool to explore the range of possible phenotypes and combinations of traits, and therewith for exploring potential constraints on adaptive evolution (Frankino et al., 2005; Brakefield, 2006).

We here explore genetic (and phenotypic) correlations, and therewith potential constraints on short-term evolutionary change, for key life-history traits by using artificial selection in the tropical butterfly Bicyclus anynana separately on each of the following traits: offspring size, development time and body size. Using the resulting upward- and downward-selection lines, we then use a common garden experiment to explore how strong and consistent associations among these traits are. Additionally, we analyse the impact of the different selection regimens on sex-related differences in sexually dimorphic traits. In particular, we will address the following issues: (1) Is a short development time negatively related to a large body size as is regularly assumed in life-history theory (e.g. Stearns and Koella, 1986; Partridge et al., 1999; Prasad et al., 2001; Roff, 2002; but see Gotthard, 2004)?; (2) Does large egg size correlate with large body size, as is commonly assumed owing to positive genetic correlations among these traits (e.g. Czesak and Fox, 2003)?; and (3) Does large egg size, and thus large hatchling size, result in reduced development time (e.g. Yampolski and Scheiner, 1996; Azevedo et al., 1997)?

\section{Materials and methods}

\section{Study organism and experimental populations}

B. anynana is a tropical, fruit-feeding butterfly distributed from southern Africa to Ethiopia (Larsen, 1991). The species exhibits striking phenotypic plasticity in the form of two seasonal morphs as an adaptation to alternative wet-dry seasonal environments and the associated changes in resting background and predation (Brakefield, 1997; Lyytinen et al., 2004). Reproduction and development is essentially confined to the warmer wet season when oviposition plants are abundantly available, and where 2-3 generations occur. During the colder dry season, reproduction ceases and butterflies do not mate before the first rains at the beginning of the next wet season (Brakefield, 1997). A laboratory stock population of $B$. anynana was established at Leiden University in 1988 from over 80 gravid females collected at a single locality in Malawi. Several hundred adults are reared in each generation, maintaining high levels of heterozygosity at neutral loci (Van't Hof et al., 2005).

We compared a total of seven lines, all of which were derived from the same stock population. One pair of lines was selected for short or long pre-adult develop- ment time, respectively (hereafter referred to as Short and Long Larval Time), another for high or low pupal mass (High and Low Pupal Mass), and the third for large or small egg size relative to body size (Large and Small Egg Size). The seventh line was the stock population itself (Control), serving as an unselected control. Selection was performed in a manner to minimize any founder effects, genetic drift or inbreeding depression (Brakefield et al., 2001). Furthermore, replicate lines have consistently shown similar responses to selection. As explained further below, our experimental design in this study ensures that individuals of each line experience the same food plant (a single stolon for each developing larva) thus increasing the reliability of the line comparisons. Unfortunately, this set-up allows for a limited number of lines/genotypes to be compared because of plant size and space requirement, which together prevented the use of replicates per line. However, the problem is to some extent reduced because all the lines used originated from the same stock population.

Selection on pre-adult development time was on the time from egg-laying (over a $12 \mathrm{~h}$ period) until adult eclosion, by selecting at least the first (Short Larval Time) or last (Long Larval Time) 50 out of 150-200 adults of each sex to enclose from pupae in each generation. In later generations, to increase selection intensity and preserve larval food supply for the final instars, selection was at two stages: a pre-selection in the mid-instar larvae (by culling the smallest (Short Larval Time) or largest (Long Larval Time) individuals) followed by further selection at eclosion (see also Brakefield and Kesbeke, 1997). For selection on pupal mass, pupae were weighed 1 day after pupation to the nearest $0.01 \mathrm{mg}$, and then stored in numbered and small plastic containers. Each line was raised in five separate sleeve cages, and before selection, pupal masses were standardized per replicate cage and sex to remove environmental variation in pupal mass. The 30-35 largest (High Pupal Mass) or smallest (Low Pupal Mass) individuals per sex were then selected to initiate the next generation. Selection was performed for 23 generations. From this point onwards mild selection was applied by selecting the pupae (separated by sex) for size by eye to maintain the phenotypic differentiation between the lines (see also Frankino et al., 2005). Selection on egg size was corrected for pupal mass by selecting on residuals. The size of ca. 10 eggs per female was measured for 100-160 females per line in each generation, from which 30 were selected as parents. As the eggs of $B$. anynana are nearly perfect spheres, egg size was measured as cross-sectional area $\left(\mathrm{mm}^{2}\right)$ using a digital camera (Leica DC200) connected to a binocular microscope (for details see Fischer et al., 2006). During selection, we also established lines selected purely on egg size. However, as could be expected from weak correlations between egg and body size (Fischer et al., 2002), there were no substantial differences between selection on egg size or residual egg size (see Fischer et al., 2006). The selection lines were some 100 (Short Larval Time), 50 (Long Larval Time), 40 (High and Low Pupal Mass), or 16 (Large and Small Egg Size) generations old (equivalent to time periods of 10 (Short and Long Larval Time), four (High and Low Pupal Mass) or two (Large and Small Egg Size) years since start of selection) at the time of setting up the present experiment. Except for the Short 
and Long Larval Time lines, all lines were fully replicated (egg size lines in triplicate, pupal mass lines in duplicate) with replicates generally showing comparable results (e.g. Fischer et al., 2006). All selected lines had been established at $27^{\circ} \mathrm{C}$, and showed significant realized heritabilities for all traits targeted by selection and in all directions of selection. Consequently, the extensive phenotypic divergence of the lines has a clear genetic basis.

\section{Common garden experiment}

All parental generation animals from the seven lines were reared in population cages within the same environmental cabinet at $27^{\circ} \mathrm{C}$, high relative humidity $(70 \%)$ and a photoperiod of L12:D12. These conditions are similar to the ones experienced by the butterflies during the favourable wet season in the field (Brakefield and Mazzotta, 1995). Larvae were fed on young maize plants, adults on moist banana. To account for variation in development time, eggs from the different lines were collected at different times (e.g. eggs from the Long and Short Larval Time lines were collected earlier or later, respectively, compared with the other lines). This procedure led to a well-synchronized adult eclosion across lines. Males and females were then allowed to mate randomly within lines. Following sufficient time for mating, about 50 females per line were allowed to oviposit on fresh maize cuttings for one 12-h light cycle. During the dark phase of the same day, eggs were carefully removed from the cuttings and weighed to the nearest $0.0001 \mathrm{mg}$ on a microbalance (Satorius Ultra Micro 4504MP8). They were then placed individually in labelled $1.5 \mathrm{ml}$ Eppendorf tubes and transferred back to the environmental cabinet. Collecting and weighing of eggs was repeated until there were sufficient eggs from all lines. Subsequently, the Eppendorf tubes were checked twice a day for hatchlings.

Hatchlings were transferred individually to 11 plastic containers (covered with gauze), containing a stolon of a potted Oplismenus africanus (P. Beauv., 1810) plant, a natural food-plant of $B$. anynana in which performance in terms of life-history traits is closely similar to that on maize (Kooi et al., 2000). The plants were propagated vegetatively, to standardize environmental conditions as far as possible. One larva from each line was reared per Oplismenus plant (i.e. seven larvae, each in a separate container, per plant). We used 100 replicate plants, resulting in 100 larvae per line. All plants with the respective larvae were kept in a single environmental cabinet $\left(27^{\circ} \mathrm{C}\right.$, high relative humidity, L12:D12 throughout). The containers were checked daily and new plants provided as necessary. Even if only one larva was about to run out of food, the whole plant was exchanged to provide uniform and favourable growing conditions. Pupae were removed from the pots and weighed to the nearest $0.01 \mathrm{mg}$ on the day following pupation. Afterwards, pupae were kept individually until adult eclosion. The position of plants within the cabinet was not changed until the final larva had pupated. For all individuals, we measured egg mass (see above), larval development time (from hatching to pupation in days), pupal mass and pupal development time (from pupation to adult eclosion). Individual larval growth rates were calculated as a mean growth rate, averaged over the larval period: growth rate $=\left(\left(\mathrm{LN}_{\text {pupal mass }}-\mathrm{LN}_{\text {hatchling mass }}\right) /\right.$ larval time)*100 (cf. Nylin, 1992; Fischer and Fiedler, 2000). Hatchling masses were calculated from egg masses based on equations given in Fischer et al. (2002).

\section{Statistical analyses}

To test for differences in life-history traits across selection lines we used two-way analysis of variance (ANOVA), with line and sex as fixed factors. As these analyses do not control for the independency of individuals within selection lines, data were additionally analysed using analysis of covariances (ANCOVAs) and regression analyses on selection line means. The former included sex as a fixed factor and different covariates (egg mass, larval development time and/or pupal mass). Throughout, correlated responses to selection are used as proxies for genetic correlations. Phenotypic correlations among traits were calculated using residuals of two-way ANOVAs with selection line and sex as fixed factors (calculating phenotypic correlations by line did not yield any additional information and are therefore not shown). Correlations were investigated by Pearson and partial regressions. For the latter, the correlation between two of the target traits for selection (e.g. egg mass and pupal mass) was calculated while controlling for the effects of the remaining trait (e.g. larval development time). Pairwise comparisons were performed employing Tukey's honestly significant difference (HSD) test. The data were also examined by principal component analyses, but as this revealed no new patterns across traits or among lines, these results are not included (but are available from the authors upon request).

\section{Results}

\section{Responses and correlated responses to selection}

Each target trait (egg size, pre-adult development time and pupal mass) differed substantially between the associated 'up' and 'down' directions; they had clearly responded to artificial selection (Table 1; Figure 1). Butterflies selected for large egg size, long pre-adult development time or high pupal mass laid, on average, $40.3 \%$ larger eggs, had $27.8 \%$ longer larval development times or $68.0 \%$ higher pupal masses than their paired lines selected in the opposite direction. Egg size was largest in the Large Egg Size line and smallest in the Small Egg Size line (Large Egg Size > High Pupal Mass > Short Larval Time $>$ Long Larval Time $=$ Control $=$ Low Pupal Mass $>$ Small Egg Size; Tukey's HSD after ANOVA); larval development time was longest in the Long Larval Time line and shortest in the Short Larval Time line (Long Larval Time $>$ High Pupal Mass $=$ Low Pupal Mass $=$ Large Egg Size $>$ Small Egg Size $=$ Control $>$ Short Larval Time; Tukey's HSD); and pupal mass was highest in the High Pupal Mass line and lowest in the Low Pupal Mass line (High Pupal Mass $>$ Large Egg Size $=$ Control $>$ Small Egg Size $=$ Long Larval Time $=$ Short Larval Time $>$ Low Pupal Mass; Tukey's HSD).

Regarding the other two traits examined, pupal development time was longest in the Large Egg Size, Long Larval Time and High Pupal Mass lines, and shortest in the Short Larval Time line (Large Egg 
Table 1 Results of two-way ANOVAs for the effects of selection line and sex on life-history traits in B. anynana

\begin{tabular}{|c|c|c|c|c|c|}
\hline Trait & Source & $d f$ & SS & F & $\mathrm{P}$ \\
\hline \multirow[t]{4}{*}{ Egg mass (mg) } & Line & 6 & 1.1798 & 273.89 & $<0.0001$ \\
\hline & Sex & 1 & 0.0003 & 0.37 & 0.55 \\
\hline & Line $\times$ sex & 6 & 0.0018 & 0.41 & 0.87 \\
\hline & Error & 545 & 0.3913 & & \\
\hline \multirow[t]{4}{*}{ Larval time (days) } & Line & 6 & 2282.8 & 25.62 & $<0.0001$ \\
\hline & Sex & 1 & 1130.4 & 76.12 & $<0.0001$ \\
\hline & Line $\times$ sex & 6 & 95.6 & 1.07 & 0.38 \\
\hline & Error & 545 & 8093.7 & & \\
\hline \multirow[t]{4}{*}{ Pupal time (days) } & Line & 6 & 41.84 & 44.58 & $<0.0001$ \\
\hline & Sex & 1 & 11.39 & 72.78 & $<0.0001$ \\
\hline & Line $x \operatorname{sex}$ & 6 & 3.08 & 3.28 & 0.0035 \\
\hline & Error & 545 & 85.26 & & \\
\hline \multirow[t]{4}{*}{ Pupal mass (mg) } & Line & 6 & 418267 & 144.69 & $<0.0001$ \\
\hline & Sex & 1 & 155857 & 323.50 & $<0.0001$ \\
\hline & Line $x \operatorname{sex}$ & 6 & 2140 & 0.74 & 0.62 \\
\hline & Error & 545 & 262572 & & \\
\hline \multirow{4}{*}{$\begin{array}{l}\text { Growth rate } \\
\left(\% \text { day }^{-1}\right)\end{array}$} & Line & 6 & 0.1769 & 26.03 & $<0.0001$ \\
\hline & Sex & 1 & 0.0442 & 39.07 & $<0.0001$ \\
\hline & Line $x \operatorname{sex}$ & 6 & 0.0048 & 0.70 & 0.65 \\
\hline & Error & 545 & 0.6172 & & \\
\hline
\end{tabular}

Abbreviation: ANOVA, analysis of variance.

Significant $P$-values are given in bold.

Size $=$ Long Larval Time $=$ High Pupal Mass $>$ Control $=$ Small Egg Size $=$ Low Pupal Mass $>$ Short Larval Time; Tukey's HSD). Thus, patterns in larval and pupal development times across lines were (at least in their tendencies) largely consistent. Finally, larval growth rates were highest in the Short Larval Time line and lowest in the Long Larval Time line (Short Larval Time= Control $=$ Small Egg Size $>$ High Pupal Mass $=$ Large Egg Size $=$ Low Pupal Mass $>$ Long Larval Time; Tukey's HSD), thus showing the opposite pattern to larval development time.

Table 2 shows the responses and correlated responses to selection as deviations from the unselected Control. These results (together with the above post hoc comparisons) indicate a positive genetic correlation between egg and body size, and show that selection on egg size yielded longer larval and pupal development times (associated with lower larval growth rates) in the Large Egg Size line. Selection on pre-adult development time led to a small increase in egg size in the Short Larval Time line, as well as a clear divergence of the Short and Long Larval Time lines for pupal development time and especially for larval growth rate. Both lines produced pupae of a similar, relatively small, size. Finally, selection on pupal mass resulted in a slight divergence in pupal time, but with larval time and larval growth rate unaffected (in both lines relatively long or low, respectively). Thus, selection on development time results in larger eggs in the Short Larval Time than in the Long Larval Time line, but the converse is not true: selection on egg size yields longer development time in the Large Egg Size than in the Small Egg Size line. Further, selection on pupal mass does not lead to a divergence in development time between Low and High Pupal Mass line, and the converse is also true: selection on develop- ment time does not affect pupal mass in the Low Larval Time relative to the High Pupal Mass line.

The above results were backed-up by correlation and ANCOVA analyses using selection line means (see Materials and methods). The correlation analyses once again demonstrate that there is no association between egg mass and larval development time, while a positive genetic correlation between egg and pupal mass is supported (note the relatively high $r$-values and the low sample sizes; Table 3a). Further, there was no clear evidence for a genetic correlation between larval development time and pupal mass. Pearson and partial correlations tended to give comparable results, although $r$-values were generally lower using partial correlations. This was especially the case for the correlations between egg mass and larval time as well as between larval time and pupal mass, indicating some influence of the respective third variable. The above patterns are also supported by ANCOVAs on egg mass, larval development time and pupal mass, where the only significant factors were pupal mass affecting egg mass and vice versa $\left(\mathrm{F}_{1,10}=6.0, P=0.034\right)$.

\section{Phenotypic correlations}

Phenotypic correlations revealed a negative association between larval time and pupal mass (Table $3 b$ ). Thus, on average, slow developing individuals achieved lower pupal masses than fast developing ones. Further, egg mass tended to be positively related to pupal mass, whereas there was no association between egg mass and larval time. Pearson and partial correlations generally gave very similar results.

\section{Sex-related differences in life-history traits}

In addition to the differences across selection lines there were as expected sex-related differences in life-history traits. Males had shorter larval development times (owing to protandry selection; Wiklund et al., 1991; Zijlstra et al., 2002), higher larval growth rates (to achieve protandry; Wiklund et al., 1991; Fischer and Fiedler, 2001), slightly longer pupal development times (but with little effect on protandry) and lower pupal masses (presumably due to fecundity selection in females; e.g. Honek, 1993). It is remarkable, however, how stable the sex difference in pupal mass is, with females being about $20 \%(19.9-22.9 \%)$ heavier than males across all lines (Figure 1d). Also, the males' developmental advantage persisted throughout, with males having a shorter development time from egg to adult eclosion than females, but with more variability across lines (3.7$9.9 \%$ ). No differences between sexes were found in egg mass (Table 1). Except for pupal development time, sex differences were consistent across selection lines as indicated by the absence of significant line-by-sex interactions. Regarding pupal time, the significant interaction indicates some marginal variation in the sex difference across selection lines, with females being $1.7-7.0 \%$ faster than males (Figure 1c).

\section{Discussion}

\section{Correlated responses to selection}

By comparing lines of the butterfly $B$. anynana artificially selected for short and long pre-adult development time, 

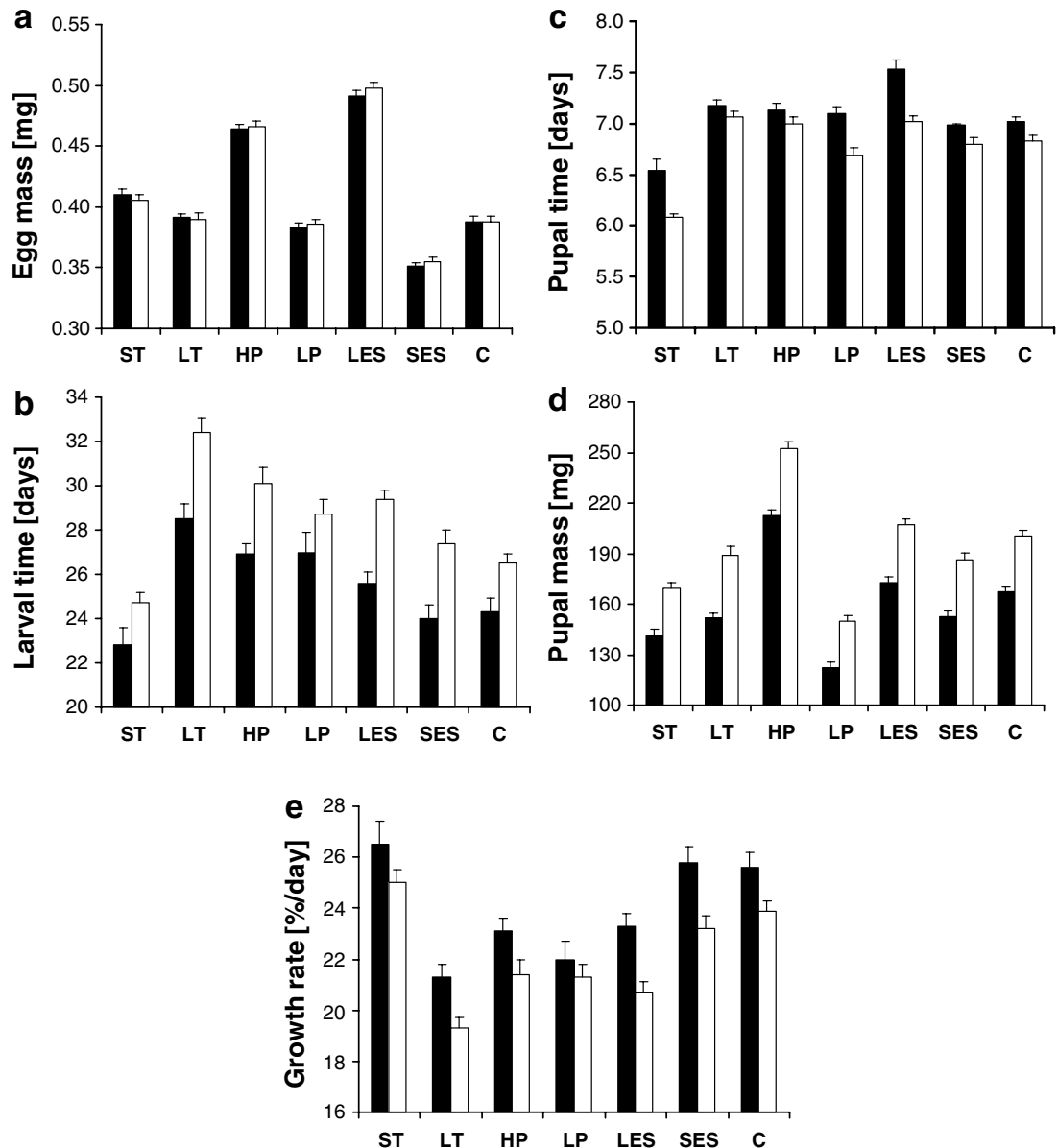

Figure 1 Egg mass (a), larval development time (b), pupal development time (c), pupal mass (d) and growth rate (e) for male (black bars) and female (open bars) B. anynana across lines selected for short (ST) and long (LT) larval development time, high (HP) and low (LP) pupal mass, large (LES) and small (SES) egg size and for an unselected stock population (C). Given are line means +1 s.e. Sample sizes range between 28 and 51 individuals per line and sex.

Table 2 Responses and correlated responses to selection for males and females of lines selected for ST and LT, HP and LP, and LES and SES

\begin{tabular}{llrrrrr}
\hline Line & Sex & $\begin{array}{r}\text { Egg } \\
\text { mass }\end{array}$ & $\begin{array}{c}\text { Larval } \\
\text { time }\end{array}$ & $\begin{array}{c}\text { Pupal } \\
\text { time }\end{array}$ & $\begin{array}{r}\text { Pupal } \\
\text { mass }\end{array}$ & $\begin{array}{r}\text { Growth } \\
\text { rate }\end{array}$ \\
\hline ST & Males & 5.7 & $-\mathbf{6 . 2}$ & -6.8 & -15.4 & 3.5 \\
& Females & 4.4 & $-\mathbf{6 . 8}$ & -11.0 & -15.4 & 4.6 \\
LT & Males & 0.8 & $\mathbf{1 7 . 3}$ & 2.1 & -9.2 & -16.8 \\
& Females & 0.5 & $\mathbf{2 2 . 3}$ & 3.4 & -5.7 & -19.2 \\
HP & Males & 19.6 & 10.7 & 1.6 & $\mathbf{2 7 . 1}$ & -9.8 \\
& Females & 20.1 & 13.6 & 2.5 & $\mathbf{2 5 . 7}$ & -10.5 \\
LP & Males & -1.3 & 11.1 & 1.1 & $-\mathbf{2 6 . 9}$ & -14.1 \\
& Females & -0.5 & 8.3 & -2.2 & $-\mathbf{2 5 . 2}$ & -10.9 \\
\multirow{2}{*}{ LES } & Males & $\mathbf{2 6 . 5}$ & 5.3 & 7.3 & 3.5 & -9.0 \\
& Females & $\mathbf{2 8 . 4}$ & 10.9 & 2.8 & 3.4 & -13.4 \\
\multirow{2}{*}{ SES } & Males & $-\mathbf{9 . 5}$ & -1.2 & -0.6 & -8.6 & 0.8 \\
& Females & $-\mathbf{8 . 5}$ & 3.4 & -0.6 & -7.3 & -2.9 \\
\hline
\end{tabular}

Abbreviations: HP, high pupal mass; LES, large egg size; LP, low pupal mass; LT, long larval development time; SES, small egg size; ST, short larval development time.

Data give the mean deviation from the unselected control in percent. Responses to selection are printed in bold. high and low pupal mass, large and small egg size and an unselected control population within a single common-garden experiment, we revealed several deviations from our predictions based on life-history theory. When considering correlated responses to selection, the Long Larval Time line showed no increase in pupal mass, and the Low Pupal Mass line showed no decrease in larval time, whereas the Short Larval Time line exhibited lower pupal masses and the High Pupal Mass line longer development times. Thus, there is ambiguous evidence and overall no clear support for the trade-off usually expected between development time and pupal mass (e.g. Stearns and Koella, 1986; Roff, 2002), as the Short and Long Larval Time lines produced pupae of a similar size. Further, larval development times and growth rates were comparable in the Low and High Pupal Mass lines with highly divergent pupal mass. Although the fact that a genetic correlation between larval development and pupal mass could not be demonstrated is certainly interesting, it does not necessarily imply that the anticipated trade-off is, in general, absent. Windig (1994) for instance, found a weak negative genetic correlation between these traits in B. anynana. Such variable outcomes might be expected in sufficiently complex multivariate systems (e.g. Pease and Bull, 
Table 3 Genetic (a) and phenotypic (b) correlations among the target traits of selection in B. anynana

\begin{tabular}{|c|c|c|c|c|c|c|c|c|c|c|c|c|}
\hline & \multicolumn{6}{|c|}{ Pearson correlations } & \multicolumn{6}{|c|}{ Partial correlations } \\
\hline & \multicolumn{2}{|c|}{ Sexes combined $\mathrm{n}=14$} & \multicolumn{2}{|c|}{ Males $\mathrm{n}=7$} & \multicolumn{2}{|c|}{ Females $\mathrm{n}=7$} & \multicolumn{2}{|c|}{ Sexes combined $\mathrm{n}=14$} & \multicolumn{2}{|c|}{ Males $\mathrm{n}=7$} & \multicolumn{2}{|c|}{ Females $\mathrm{n}=7$} \\
\hline & $\mathrm{r}$ & $P$ & $\mathrm{r}$ & $\mathrm{P}$ & $\mathrm{r}$ & $P$ & $\mathrm{r}$ & $P$ & $\mathrm{r}$ & $\mathrm{P}$ & $\mathrm{r}$ & $P$ \\
\hline \multicolumn{13}{|l|}{ (a) } \\
\hline Egg mass - larval time & 0.192 & 0.511 & 0.170 & 0.716 & 0.263 & 0.569 & -0.081 & 0.793 & 0.108 & 0.839 & 0.092 & 0.863 \\
\hline Egg mass - pupal mass & 0.554 & 0.040 & 0.638 & 0.123 & 0.629 & 0.130 & 0.533 & 0.060 & 0.630 & 0.180 & 0.567 & 0.211 \\
\hline Larval time - pupal mass & 0.455 & 0.102 & 0.137 & 0.769 & 0.311 & 0.498 & 0.427 & 0.146 & 0.038 & 0.943 & 0.193 & 0.714 \\
\hline & \multicolumn{2}{|c|}{$\mathrm{n}=559$} & \multicolumn{2}{|c|}{$\mathrm{n}=261$} & \multicolumn{2}{|c|}{$\mathrm{n}=298$} & \multicolumn{2}{|c|}{$\mathrm{n}=559$} & \multicolumn{2}{|c|}{$\mathrm{n}=261$} & \multicolumn{2}{|c|}{$\mathrm{n}=298$} \\
\hline Egg mass - larval time & -0.031 & 0.472 & -0.051 & 0.409 & -0.015 & 0.798 & 0.028 & 0.518 & 0.015 & 0.806 & 0.038 & 0.511 \\
\hline Egg mass - pupal mass & 0.124 & 0.003 & 0.140 & 0.024 & 0.115 & 0.047 & 0.124 & 0.003 & 0.131 & 0.035 & 0.120 & 0.038 \\
\hline Larval time - pupal mass & -0.442 & $<0.001$ & -0.464 & $<0.001$ & -0.428 & $<0.001$ & -0.441 & $<0.001$ & -0.462 & $<0.001$ & -0.429 & $<0.001$ \\
\hline
\end{tabular}

In partial correlations, it was controlled for the effects of the third trait (i.e. in the correlations between egg mass and larval time it was controlled for effects of pupal mass etc.). For genetic correlations, selection line means were used, and for phenotypic correlations the residuals of two-way ANOVAs with selection line and sex as fixed factors. Correlations with $P<0.05$ are printed in bold.

1988; Blows and Hoffmann, 2005). Further, development time is related to wing patterns in B. anynana (Zijlstra et al., 2003, 2004). Which impact this may have on genetic correlations among other traits is currently unclear.

The increased larval development time in the Large Egg Size compared with the Small Egg Size line was also unexpected as it is commonly assumed that larger egg (and hatchling) size reduces, rather than increases larval time (e.g. Yampolski and Scheiner, 1996; Azevedo et al., 1997). On the other hand there was an increase in egg size in the Short Larval Time line. These contradictory results allow no firm conclusions about the genetic correlation between development time and egg size; it appears to depend on the specific selection regime or its longer-term stability (note the considerable difference in selection history between egg size and development time lines, see Materials and methods; see also Phelan et al., 2003). However, the fact that genetic correlations may break down given enough time does not explain why there is at least a trend towards the expected direction in the older Short and Long Larval Time lines, but not in the much younger Large and Small Egg Size lines. Thus, there is no evidence that our results were considerably affected by differences in selection history.

In summary, our results provide no clear support for the existence of genetic correlations between development time and either egg size or pupal mass, but do support the assumption of a positive genetic correlation between egg and body size (Fox and Czesak, 2000; Czesak and Fox, 2003). Regarding the latter, however, it should be noted that, when selecting on egg size in $B$. anynana, there was only very weak evidence for a correlated response in pupal mass, even when selection was on egg size only (i.e. not corrected for body size; Fischer et al., 2006). Thus, it seems that selection on body size does yield a correlated response in egg size (Tables 1 and 3; Fischer et al., 2002), whereas the opposite trend is fairly weak (see also Tucic et al., 1998). Thus, correlated responses in life-history traits were frequently not consistent with expectations and were, overall, rather unpredictable (cf. Gromko, 1995). It is important to note that our results are not confounded by differences in the founding population of the selected lines, as they all originated from the same population.

\section{Phenotypic correlations}

Correlation analyses revealed that a longer development is associated with a lower pupal mass and that egg mass tended to be positively related to pupal mass, whereas there was no association between egg mass and larval time. Overall patterns were not substantially affected by variation in third traits. For the relationship between egg mass and development time (no association) as well as that between egg mass and pupal mass (a positive association) genetic and phenotypic correlations gave comparable results, although this was not true for the relation between development time and pupal mass. No genetic correlation was found for the latter, but a rather clear negative phenotypic correlation. Such differences between genetic and phenotypic correlations in lifehistory data have long been known (Rose and Charlesworth, 1981; Reznick, 1985), although both approaches tend to be similar when sample sizes are large $(>50)$ and estimates are reliable (e.g. Cheverud, 1988; Stearns, 1992).

\section{Sexually dimorphic traits}

All the differences between males and females found were as expected and confirmed existing data (see above). The finding that protandry (earlier male emergence) persisted in all lines regardless of variation in development time and body size further strengthens the support for the notion that it is caused by sexual selection and is not merely a by-product of differences in body size (Nylin et al., 1993; Fischer and Fiedler, 2000; Zijlstra et al., 2002). Further, it is striking how strongly canalized the sexual size dimorphism is, even though our selection lines cover a wide range in body size (Figure 1). Thus, body size seems to be highly genetically correlated across sexes.

\section{Conclusions}

Contrary to predictions, neither the analysis of phenotypic or genetic correlations among key life history traits revealed a consistent positive association between development time and pupal mass, nor a negative one between egg size and developmental time. On the other hand there was clear evidence for a positive genetic correlation between egg and body size, which may 
'constrain' the independent evolutionary change of both traits (this issue is currently under further investigation). However, there was no indication for a trade-off between development time and pupal mass. The measurement of both trade-offs and constraints has attracted substantial criticism and controversy (Gould and Lewinton, 1979; Pease and Bull, 1988; Stearns, 1992; Pigliucci and Kaplan, 2000; Sgrò and Hoffmann, 2004; Frankino et al., 2005). The following reasons for why an expected trade-off might not be found in practice have been suggested (Stearns, 1992): first, phylogenetic fixation as an invariant physiological mechanism; second, income breeding (i.e. drawing on adult diet for reproduction) and/or lack of shared energy reserves; third, variation in acquisition and allocation of energy; and fourth, genotype-environment interactions. Further, relationships among lifehistory traits may at least in part depend on random effects such as inbreeding and genetic drift or may be special to the population under consideration. These issues are particularly relevant in our case as there was no replication of selection lines and all lines originated from the same population (making any extrapolations to the species level untrustworthy). In our analyses we were primarily interested in the identification of patterns of genetic correlations among key developmental traits. These, should be viewed as one out of many on principle possible scenarios and thus as a demonstration of the wide variability in relationships among specific traits, rather than as some general pattern.

Of the issues raised above, potential differences in the acquisition and allocation of energy seem to be of particular relevance. If such differences occur among our selected lines, however, they would be associated with differences in genotype, that is, would be part of the genetic correlations. It is also important to bear in mind that our experiment was carried under beneficial conditions when trade-offs may be masked (e.g. Van Noordwijk and De Jong, 1986; Reznick et al., 2000; Messina and Fry, 2003). This issue certainly deserves further investigation.

\section{Acknowledgements}

This manuscript greatly benefited from insightful comments provided by $F$ Messina and two anonymous referees. We thank $\mathrm{N}$ Wurzer and $\mathrm{M}$ Lavrijsen for the supply of maize plants. Funding was provided by Leiden University, the German Research Council (DFG Grant no. Fi 846/1-2 and 1-3 to KF) and The Netherlands Organization for Scientific Research (NWO 811-34.005 to BJZ).

\section{References}

Azevedo RBR, French V, Partridge L (1997). Life-history consequences of egg size in Drosophila melanogaster. Am Nat 150: $250-282$.

Blanckenhorn WU (2000). The evolution of body size: what keeps organisms small? Quart Rev Biol 75: 385-407.

Blows MW, Hoffmann AA (2005). A reassessment of genetic limits to evolutionary change. Ecology 86: 1371-1384.

Brakefield PM (1997). Phenotypic plasticity and fluctuating asymmetry as responses to environmental stress in the butterfly Bicyclus anynana. In: Bijlsma RR, Loeschke V (eds). Environmental Stress: Adaptation and Evolution. Birkhäuser: Basel, pp 65-78.
Brakefield PM (2006). Evo-devo and constraints on selection. Trends Ecol Evol 21: 362-368.

Brakefield PM, El Filali E, van der Laan R, Breuker CJ, Saccheri IJ, Zwaan BJ (2001). Effective population size, reproductive success and sperm competition in the butterfly, Bicyclus anynana, in captivity. J Evol Biol 14: 148-156.

Brakefield PM, Kesbeke F (1997). Genotype-environment interactions for insect growth in constant and fluctuating temperature regimes. Proc $R$ Soc Lond B 264: 717-723.

Brakefield PM, Mazzotta V (1995). Matching field and laboratory environments - effects of neglecting daily temperaturevariation on insect reaction norms. J Evol Biol 8: 559-573.

Cheverud JM (1988). A comparison of genetic and phenotypic correlations. Evolution 42: 958-968.

Czesak ME, Fox CW (2003). Evolutionary ecology of egg size and number in a seed beetle: genetic trade-off differs between environments. Evolution 57: 1121-1132.

Falconer DS, Mackay TFC (1996). Introduction to Quantitative Genetics, 2nd edn. Longman Scientific: New York.

Fischer K, Bot ANM, Brakefield PM, Zwaan BJ (2003). Fitness consequences of temperature-mediated egg size plasticity in a butterfly. Funct Ecol 17: 803-810.

Fischer K, Bot ANM, Brakefield PM, Zwaan BJ (2006). Do mothers producing large offspring have to sacrifice fecundity? J Evol Biol 19: 380-391.

Fischer K, Fiedler K (2000). Sex-related differences in reaction norms in the butterfly Lycaena tityrus (Lepidoptera: Lycaenidae). Oikos 90: 372-380.

Fischer K, Fiedler K (2001). Dimorphic growth patterns and sexspecific reaction norms in the butterfly Lycaena hippothoe sumadiensis. J Evol Biol 14: 210-218.

Fischer K, Zwaan BJ, Brakefield PM (2002). How does egg size relate to body size in butterflies? Oecologia 131: 375-379.

Fox CW, Czesak ME (2000). Evolutionary ecology of progeny size in arthropods. Annu Rev Entomol 45: 341-369.

Frankino WA, Zwaan BJ, Stern DL, Brakefield PM (2005). Natural selection and developmental constraints in the evolution of allometries. Science 307: 718-720.

Gotthard K (2004). Growth strategies and optimal body size in temperate Pararginii butterflies. Integr Comp Biol 44: 471-479.

Gould SJ, Lewinton RC (1979). The Spandrels of San Marco and the Panglossian paradigm: a critique of the adaptationist programme. Proc $R$ Soc Lond B 205: 581-598.

Gromko MH (1995). Unpredictability of correlated response to selection - pleiotropy and sampling interact. Evolution 49: 685-693.

Hill WG, Caballero A (1992). Artificial selection experiments. Annu Rev Ecol Syst 23: 287-310.

Honek A (1993). Intraspecific variation in body size and fecundity in insects: a general relationship. Oikos 66: 483-492.

Houle D (1991). Genetic covariance of fitness correlates - What genetic correlations are made of and why it matters. Evolution 45: 630-648.

Kooi RE, van Binnendijk E, Brakefield PM (2000). Effects of larval food on development time and fat content in the tropical butterfly Bicyclus annana. Proc Exper Appl Entomol 11: $55-60$.

Larsen TB (1991). The Butterflies of Kenya. University Press: Oxford.

Lyytinen A, Brakefield PM, Lindström L, Mappes J (2004). Does predation maintain eyespot plasticity in Bicyclus anynana? Proc R Soc Lond B 271: 279-283.

Maynard-Smith J, Burian R, Kauffmann S, Alberch P, Campbell J, Goodwin B et al. (1985). Developmental constraints and evolution. Quart Rev Biol 60: 265-287.

Messina FJ, Fry JD (2003). Environment-dependent reversal of a life history trade-off in the seed beetle Callosobruchus maculatus. J Evol Biol 16: 501-509.

Nylin S (1992). Seasonal plasticity in life history traits: growth and development in Polygonia c-album (Lepidoptera: Nymphalidae). Biol J Linn Soc 47: 301-323. 
Nylin S, Wiklund C, Wickman P-O, Garcia-Barros E (1993). Absence of trade-offs between sexual size dimorphism and early male emergence in a butterfly. Ecology 74: 1414-1427.

Partridge L, French V (1996). Thermal evolution of ectotherm body size: why get big in the cold? In: Johnston IA, Bennett AF (eds). Animals and Temperature: Phenotypic and Evolutionary Adaptation. University Press: Cambridge, pp 265-292.

Partridge L, Langelan R, Fowler K, Zwaan B, French V (1999). Correlated responses to selection on body size in Drosophila melanogaster. Genet Res 74: 43-54.

Pease CM, Bull JJ (1988). A critique of methods for measuring life history trade-offs. J Evol Biol 1: 293-303.

Phelan JP, Archer MA, Beckman KA, Chippindale AK, Nusbaum TJ, Rose MR (2003). Breakdown in correlations during laboratory evolution. I. Comparative analyses of Drosophila populations. Evolution 57: 527-535.

Pigliucci M, Kaplan J (2000). The fall and rise of Dr Pangloss: adaptationism and the Spandrels paper 20 years later. Trends Ecol Evol 15: 66-70.

Prasad NG, Joshi A (2003). What have two decades of laboratory life-history evolution studies on Drosophila melanogaster taught us? J Genetic 82: 45-76.

Prasad NG, Shakarad M, Anitha D, Rajamani M, Joshi A (2001). Correlated responses to selection for faster development and early reproduction in Drosophila: the evolution larval traits. Evolution 55: 1363-1372.

Reznick D (1985). Costs of reproduction - an evaluation of the empirical evidence. Oikos 44: 257-267.

Reznick D, Nunney L, Tessier A (2000). Big houses, big cars, superfleas and the costs of reproduction. Trends Ecol Evol 15: 421-425.

Roff DA (1997). Evolutionary Quantitative Genetics. Chapman and Hall: New York.

Roff DA (2002). Life History Evolution. Sinauer Associates: Sunderland, MA.

Rose MR, Charlesworth B (1981). Genetics of life-history in Drosophila melanogaster. 1. Sib analyses of adult females. Genetics 97: 172-186.

Schmidt-Nielsen K (1984). Scaling: Why is Animal Size so Important? University Press: Cambridge.
Sgrò CM, Hoffmann AA (2004). Genetic correlations, tradeoffs and environmental variation. Heredity 93: 241-248.

Stearns SC (1989). Trade-offs in life history evolution. Funct Ecol 3: 259-268.

Stearns SC (1992). The Evolution of Life Histories. Oxford University Press: New York.

Stearns SC, Koella JC (1986). The evolution of phenotypic plasticity in life-history traits: predictions of reaction norms for age and size at maturity. Evolution 40: 893-913.

Tucic N, Gliksman I, Seslija D, Stojkovic O, Milanovic D (1998). Laboratory evolution of life-history traits in the bean weevil (Acanthoscelides obtectus): the effects of selection on developmental time in populations with different previous history. Evolution 52: 1713-1725.

Van Noordwijk AJ, De Jong G (1986). Acquisition and allocation of resources: their influence on variation in life history tactics. Am Nat 128: 137-142.

Van't Hof AE, Zwaan BJ, Saccheri IJ, Daly D, Bot ANM, Brakefield PM (2005). Characterization of 28 microsatellite loci for the butterfly Bicyclus anynana. Mol Ecol Notes 5: 169-172.

Wiklund C, Nylin S, Forsberg J (1991). Sex-related variation in growth rate as a result of selection for large size and protandry in a bivoltine butterfly (Pieris napi L). Oikos 60: 241-250.

Windig JJ (1994). Genetic correlations and reaction norms in the wing pattern of the tropical butterfly Bicyclus anynana. Heredity 73: 459-470.

Yampolski LY, Scheiner SM (1996). Why larger offspring at lower temperatures? A demographic approach. Am Nat 147: 86-100.

Zijlstra WG, Kesbeke F, Zwaan BJ, Brakefield PM (2002). Protandry in the butterfly Bicyclus anynana. Evol Ecol Res 4: 1229-1240

Zijlstra WG, Steigenga MJ, Brakefield PM, Zwaan BJ (2003). Simultaneous selection on two fitness-related traits in the butterfly Bicyclus anynana. Evolution 57: 1852-1862.

Zijlstra WG, Steigenga MJ, Koch PB, Zwaan BJ, Brakefield PM (2004). Butterfly selected lines explore the hormonal basis of interactions between life histories and morphology. Am Nat 163: E76-E87. 